\title{
High prevalence of vitamin D deficiency in children and adolescents with type 1 diabetes
}

\author{
Marco Janner $^{a}$, Pietro Ballinari ${ }^{b}$, Primus E. Mullis ${ }^{a}$, Christa E. Flück $^{a}$ \\ a Department of Paediatrics, Division of Endocrinology, Diabetology \& Metabolism, Children's Hospital, University of Berne, Berne, Switzerland \\ ${ }^{b}$ Statistician, Department of Psychiatric Neurophysiology, University Hospital of Psychiatry, Berne 60, Switzerland
}

\author{
Correspondence: \\ Marco Janner MD \\ Paediatric Endocrinology and Diabetology \\ University Children's Hospital Bern \\ Freiburgstrasse 15 / G3 811 \\ $\mathrm{CH}-3010$ Bern \\ marco.janner@insel.ch
}

\section{Summary}

Background: Vitamin D is important for bone health. An inadequate supply of vitamin D to the body is associated with a higher fracture risk in the elderly. Young adults with type 1 diabetes are reported to have a lower peak bone mass than healthy individuals, which could possibly lead to an increased fracture risk in the future. The prevalence of vitamin D deficiency in healthy young people is high. Thus, optimal supply of vitamin D may be of particular importance for bone health in children with type 1 diabetes.

Methods: In this prospective cross-sectional study we measured serum 25-hydroxy-vitamin D, iPTH, total and ionised calcium, phosphate, and alkaline phosphatase in 129 Swiss children and adolescents with type 1 diabetes.

Results: Of the 129 subjects 78 (60.5\%) were vitamin $\mathrm{D}$ deficient, defined as a 25-hydroxy-vitamin-D level below $50 \mathrm{nmol} / \mathrm{L}$. During the winter this number rose to 84.1\%. 25-hydroxy-vitamin-D levels showed marked seasonal fluctuations, whereas there was no correlation with diabetes control. Despite the high prevalence of vitamin D deficiency, we found a low prevalence of secondary hyperparathyroidism in vitamin D deficient diabetic children and adolescents.

Conclusions: Prevalence of vitamin D deficiency in diabetic children and adolescents is high. Therefore, screening for vitamin D deficiency and supplementation in children with low vitamin D levels may be considered.

Key words: vitamin D deficiency; type 1 diabetes, parathyroid hormone; 25-OH-cholecalciferol

\section{Introduction}

Vitamin D has a major impact on bone health. Severe vitamin $\mathrm{D}$ deficiency is associated with rickets in the grow- ing skeleton [1] and osteomalacia in adults [2]. In addition, low serum vitamin D levels are associated with a higher fracture risk in elderly people [3]. Furthermore, vitamin D deficiency is common in healthy children at a variety of different latitudes [4-18] and in children with type 1 diabetes mellitus (T1D), in whom the highly variable prevalence ranges between $15-65 \%$ at the end of winter [19-21].

Body vitamin D stores in an individual are assessed by measuring serum 25-hydroxy-vitamin D (25D) levels. However, there is no consensus on the 25D levels that are to be considered sufficient in children. The American Academy of Pediatrics (AAP) has defined vitamin deficiency as serum 25D below $27.5 \mathrm{nmol} / \mathrm{L}$ [22]. In infants and children, however, rickets is already seen at $25 \mathrm{D}$ levels below $37.5 \mathrm{nmol} / \mathrm{L}[8,23]$. In adolescents $25 \mathrm{D}$ levels below $40 \mathrm{nmol} / \mathrm{L}$ are associated with unphysiologically high intact parathyroid hormone (iPTH) levels and low mean forearm bone mineral density [17]. In adults the use of biomarkers such as serum PTH concentration or intestinal calcium absorption rate has recently been recommended to define biologically relevant circulating 25D levels [1]. This recommendation is based on the observation that both the intestinal calcium absorption rate increases significantly with rising $25 \mathrm{D}$ concentrations until a concentration of $75 \mathrm{nmol} / \mathrm{L}$ is reached and PTH levels also start to increase even at $25 \mathrm{D}$ concentrations below $75 \mathrm{nmol} / \mathrm{L}$ [24, 25]. Furthermore, $25 \mathrm{D}$ concentrations above $75 \mathrm{nmol} / \mathrm{L}$ appear to be important for optimal bone health, prevention of colorectal cancer and other health issues [1, 26, 27]. Hence, as stated, a 25D cut-off value of above $75 \mathrm{nmol} / \mathrm{L}$ for vitamin D sufficiency and a 25D cut-off value below 50 $\mathrm{nmol} / \mathrm{L}$ for vitamin $\mathrm{D}$ deficiency were adopted in our study $[1,20,25]$.

Clinical studies show that adolescents with T1D have a lower bone mass compared to their peers [28]. Similarly, adults with T1D are found to be at higher risk of osteoporosis and at higher risk of osteoporosis-related fractures [28].

In addition, some studies suggest a blunted response of the PTH to low levels of vitamin D in diabetic patients further deregulating calcium homeostasis [29-31]. Therefore, children with both conditions, T1D and vitamin D deficiency, may have an increased risk of bone fragility. Inad- 
equate levels of PTH for a given low serum calcium value could be an aggravating factor in this setting.

The purpose of this study was to assess the prevalence of vitamin D deficiency in patients with T1D and to define factors such as duration of diabetes, $\mathrm{HbA}_{1 \mathrm{c}}$, age, body mass index and seasonality which may possibly influence serum vitamin D levels. Additionally, we determined serum iPTH concentrations to assess secondary hyperparathyroidism in patients with vitamin D deficiency. For this purpose we conducted a prospective, cross-sectional study in children and adolescents with T1D seen at our outpatient clinic in Bern, Switzerland.

\section{Subjects and methods}

\section{Study subjects}

This study was approved by the institutional review board of the Inselspital at the University of Bern. The participants in this cross-sectional study were enrolled at the time of their regularly scheduled annual visit to our outpatient clinic. At study start, 130 patients with T1D previously diagnosed according to the diagnostic criteria of the American Diabetes Association [32] were examined at our outpatient clinic. All 130 patients agreed to participate and were thus included in the study. One patient was excluded from further analysis because of hyperparathyroidism $(215 \mathrm{pg} / \mathrm{ml})$ not explained by low vitamin D levels. We categorised each participant's study visit according to seasons as follows: Winter (22 December- 21 March), spring (22 March - 21 June), summer (22 June - 22 September) and autumn (23 September - 21 December). 44 participants were examined in winter, 20 in spring, 34 in summer and 31 in autumn.

A nutritional questionnaire enquiring into daily consumption of dairy products and calcium-rich mineral water was used to assess daily calcium intake (see appendix for details). All participants underwent a general physical examination. Standard auxological assessment was performed [33]. Measurements of weight were obtained to the nearest $0.1 \mathrm{~kg}$ using a Seca scale (Seca GmbH, Hamburg, Germany) and measurements of height were obtained to the nearest $0.1 \mathrm{~cm}$ using an Ulmer Stadiometer (Busse design, Ulm, Germany). Body mass index (BMI) was calculated as weight (kilograms) divided by height squared (square meters) [34].

Eight patients were excluded from evaluation of the PTH - vitamin D axis because measurements of ionised calcium concentration were not available for technical reasons.

\section{Laboratory findings}

Serum 25D was determined using a competitive chemiluminescence immunoassay (DPC Immulite 2500, Liaison, DiaSorin Inc., Minneapolis, USA). The between run CV was $8.4 \%$. 25D levels below $50 \mathrm{nmol} / \mathrm{L}$ were defined as vitamin D deficient [1], 25D levels between 50 and 75 $\mathrm{nmol} / \mathrm{L}$ were defined as vitamin $\mathrm{D}$ insufficient and $25 \mathrm{D}$ levels above $75 \mathrm{nmol} / \mathrm{L}$ were defined as vitamin D sufficient. Serum intact PTH (iPTH) was determined using an electro-chemiluminescent immune assay (Roche Modular E170, Roche Diagnostics Corp., Indianapolis, USA).
The reference values for iPTH were 9-59 pg/ml (6-9.9 years), $11-74 \mathrm{pg} / \mathrm{ml}$ (10-13.9 years), $9-69 \mathrm{pg} / \mathrm{ml}$ (14-17.9 years) and $10-65 \mathrm{pg} / \mathrm{ml}$ (adults). Serum ionised calcium was measured at a $\mathrm{pH}$ of 7.40 and $37{ }^{\circ} \mathrm{C}$ using an ion-selective electrode (Radiometer ABL800, Radiometer Gm$\mathrm{bH}$, Thalwil, Switzerland). Serum alkaline phosphatase was determined by a standard colorimetric assay on a Roche Modular P800 (Roche Diagnostics Corp.). $\mathrm{HbA}_{1 \mathrm{c}}$ was assessed using a latex immunoagglutination method standardised to the DCCT assay with a reference range of 4.5-5.6\% (DCA 2000+, Siemens Co. Dublin, Ireland).

\section{Statistical analysis}

Results are expressed as mean $\pm 95 \%$ confidence interval $(95 \% \mathrm{CI})$ unless otherwise stated. Statistical analysis was performed using the SPSS 17 (www.spss.com) statistics program. For detailed analysis, participants were divided into three groups according to their 25-OHD levels: $>75$ $\mathrm{nmol} / \mathrm{L}$ : vitamin D sufficient, $50-75 \mathrm{nmol} / \mathrm{L}$ : vitamin D insufficient, $<50 \mathrm{nmol} / \mathrm{L}$ : vitamin D deficient. Differences between groups were analysed by one-way ANOVA. Cross tabulation analysis with $\chi^{2}$ - test was performed for analysis of frequencies and the results plotted in a $3 \times 4$ contingency table. Adjusted residuals were calculated to show which cell was over- or underrepresented.

\section{Results}

We assessed clinical and laboratory findings in 129 children and adolescents with T1D. None of the participants had bone deformities or a history of low intensity trauma fractures. 69 participants (53.5\%) were males 60 (46.5\%) were females. Most of the participants were white (123; $95.3 \%)$, the remaining being Indian $(4 ; 3.1 \%)$, East-Asian $(1 ; 0.8 \%)$ and black $(1 ; 0.8 \%)$. The characteristics of the whole group and those of the three subgroups related to vitamin D levels are shown in table 1. No statistically significant differences in patients' characteristics between the

Figure 1

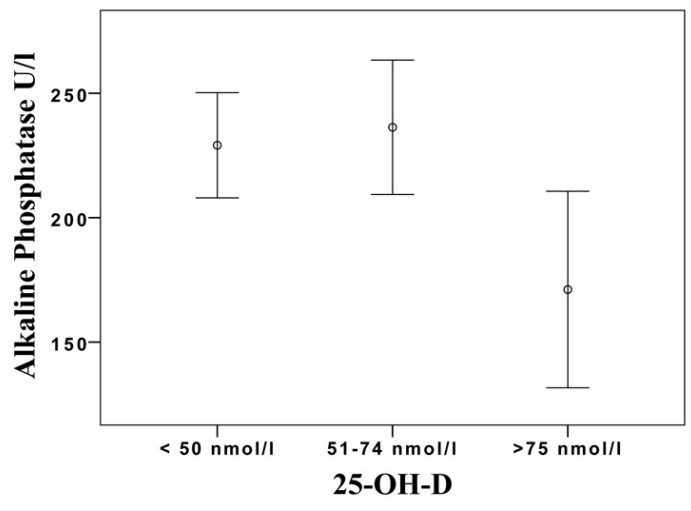

Figure 1

Alkaline phosphatase (mean $\pm 95 \%$ confidence intervals) according to 25-OH-D levels

One-way-ANOVA showed significant difference between the means $(p=0.03)$. The graph shows that alkaline phosphatase was significantly lower in participants with 25-OH-D levels above 75 $\mathrm{nmol} / \mathrm{L}$. 
three subgroups were found by one-way ANOVA. 87\% (n: 112) of the patients with T1D had 25D levels below 75 $\mathrm{nmol} / \mathrm{L}$, whereas $60.5 \%$ (n:78) were vitamin D deficient with $25 \mathrm{D}$ levels below $50 \mathrm{nmol} / \mathrm{L}$. Calcium intake and the results of calcium and phosphate metabolism are shown in table 2 . The only variable showing statistically significant differences between the three subgroups as tested by one-way-ANOVA was alkaline phosphatase $(\mathrm{F}=3.592, \mathrm{p}$ $=0.03$ ). A plot for means with $95 \%$ confidence shows that alkaline phosphatase in both vitamin D deficient and vitamin D insufficient groups was significantly higher than in the vitamin D sufficient (fig. 1). It is important to stress that neither calcium intake, age, duration of diabetes, HbAlc nor serum magnesium concentration did explain any of the variance of serum $25 \mathrm{D}$ levels.

Cross tabulation revealed a highly significant effect of season on the levels of 25D $\left(\chi^{2}=38.9, p<0.001\right) .98 \%$ of patients seen during the winter period, $90 \%$ of patients seen during spring, and $90 \%$ of patients seen in the autumn presented with $25 \mathrm{D}$ levels below $75 \mathrm{nmol} / \mathrm{L}$ (table 3). By contrast, only $68 \%$ of patients seen in the summer presented with 25D levels below $75 \mathrm{nmol} / \mathrm{L}$. Analysis of adjusted residuals showed that during winter and spring there were relatively more vitamin $\mathrm{D}$ deficient patients than in the yearly average, whereas in autumn the number of vit- amin D deficient, insufficient and sufficient patients corresponded approximately to the yearly average. Furthermore, only during the months of July, August and September did more than $75 \%$ of the patients show $25 \mathrm{D}$ levels of above 50 $\mathrm{nmol} / \mathrm{L}$ (fig. 2).

We found that iPTH was similar in all three subgroups (table 2). Three (3.8\%) patients with vitamin D levels $<50$ $\mathrm{nmol} / 1$ had hyperparathyroidism defined as $\mathrm{PTH}$ above +2 SD for age. Eight patients (26\%) with very low 25D levels $(<25 \mathrm{nmol} / \mathrm{L})$ were found to have iPTH levels above $50 \mathrm{pg} /$ $\mathrm{ml}$ but only two were elevated above $2 \mathrm{SD}$ for age qualifying for a diagnosis of secondary hyperparathyroidism.

\section{Discussion}

Our participants with T1D were found to have a high prevalence of vitamin D deficiency. Vitamin D levels showed a marked seasonal fluctuation. Additionally, vitamin D deficient children and adolescents with T1D have a low prevalence of secondary hyperparathyroidism.

It is of importance to state that the sample size is representative for a number of children and adolescents suffering from T1D in the area: the Canton of Bern has a population of 962 982. Considering the registered incidence of T1D in children and adolescents of $15 / 100000$ per year in

\begin{tabular}{|c|c|c|c|c|c|c|c|c|}
\hline \multicolumn{9}{|l|}{$\begin{array}{l}\text { Table } 1 \\
\text { Patient characteristics. }\end{array}$} \\
\hline & \multicolumn{2}{|c|}{ Total $(n=129)$} & \multicolumn{2}{|c|}{$\begin{array}{l}\text { Vitamin D sufficient }(n=17) \\
25-O H-D>75 \mathrm{nmol} / \mathrm{L}\end{array}$} & \multicolumn{2}{|c|}{$\begin{array}{l}\text { Vitamin D insufficient }(\mathrm{n}=34) \\
\text { 25-OH-D 50-75 nmol/L }\end{array}$} & \multicolumn{2}{|c|}{$\begin{array}{l}\text { Vitamin D deficient }(n=78) \\
25-\mathrm{OH}-\mathrm{D}<50 \mathrm{nmol} / \mathrm{L}\end{array}$} \\
\hline & Mean & $95 \% \mathrm{Cl}$ & Mean & $95 \% \mathrm{Cl}$ & Mean & $95 \% \mathrm{Cl}$ & Mean & $95 \% \mathrm{Cl}$ \\
\hline Age, years & 11.6 & $11.0-12.3$ & 12.5 & $10.5-14.5$ & 10.9 & $9.6-12.2$ & 11.7 & $10.8-12.6$ \\
\hline Weight-SDS & 0.13 & $-0.02-0.28$ & -0.04 & $-0.6-0.53$ & 0.23 & $-0.02-0.48$ & 0.12 & $-0.07-0.32$ \\
\hline Height-SDS & 0.06 & $-0.11-0.22$ & -0.10 & $-0.57-0.38$ & -0.02 & $-0.34-0.34$ & 0.12 & $-0.1-0.33$ \\
\hline BMI-SDS & 0.14 & $0.0-0.29$ & -0.02 & $-0.47-0.43$ & 0.31 & $0.06-0.56$ & 0.11 & $-0.09-0.3$ \\
\hline Duration of diabetes, years & 4.9 & $4.3-5.5$ & 5.8 & $4.0-7.7$ & 4.0 & $3.0-4.9$ & 5.1 & $4.3-6.6$ \\
\hline $\mathrm{HbA}_{1 \mathrm{c}} \%$ & 8.1 & 7.9-8.4 & 8.1 & $7.7-8.6$ & 7.9 & $7.7-8.2$ & 8.2 & $7.9-8.6$ \\
\hline \multicolumn{9}{|l|}{$\begin{array}{l}\text { Table } 2 \\
\text { Results. }\end{array}$} \\
\hline & \multicolumn{2}{|c|}{ Total $(n=129)$} & \multicolumn{2}{|c|}{$\begin{array}{l}\text { Vitamin D sufficient }(n=17) \\
25-O H-D>75 \mathrm{nmol} / \mathrm{L}\end{array}$} & \multicolumn{2}{|c|}{$\begin{array}{l}\text { Vitamin D insufficient }(\mathrm{n}=34 \text { ) } \\
\text { 25-OH-D 50-75 nmol/L }\end{array}$} & \multicolumn{2}{|c|}{$\begin{array}{l}\text { Vitamin D deficient }(n=78) \\
25-\mathrm{OH}-\mathrm{D}<50 \mathrm{nmol} / \mathrm{L}\end{array}$} \\
\hline & Mean & $95 \% \mathrm{Cl}$ & Mean & $95 \% \mathrm{Cl}$ & Mean & $95 \% \mathrm{Cl}$ & Mean & $95 \% \mathrm{Cl}$ \\
\hline Calcium intake, $\mathrm{mg} / \mathrm{d}^{1}$ & 845.3 & $760.6-930.0$ & 822.4 & 672.6-972.1 & 920.9 & $738.1-1103.6$ & 818.0 & 704.3-931.7 \\
\hline Calcium, mmol/L & 2.36 & $2.34-2.37$ & 2.35 & $2.31-2.38$ & 2.37 & $2.34-2.4$ & 2.35 & $2.34-2.37$ \\
\hline $\mathrm{Ca}^{2+}, \mathrm{mmol} / \mathrm{L}$ & 1.22 & $1.22-1.23$ & 1.22 & $1.21-1.23$ & 1.24 & $1.22-1.25$ & 1.22 & $1.21-1.23$ \\
\hline Phosphate, $\mathrm{mmol} / \mathrm{L}$ & 1.41 & $1.38-1.44$ & 1.41 & $1.34-1.49$ & 1.38 & $1.31-1.44$ & 1.43 & $1.38-1.47$ \\
\hline Magnesium, mmol/L & 0.81 & $0.80-0.82$ & 0.80 & $0.78-0.83$ & 0.81 & $0.79-0.82$ & 0.82 & $0.80-0.83$ \\
\hline Alk. Phosphatase U/I & 223 & $208-239$ & 171 & $132-211$ & 236 & $209-263$ & 230 & $208-250$ \\
\hline iPTH, pg/ml ${ }^{2}$ & 35.8 & $33.3-38.3$ & 34.8 & $29.2-40.5$ & 31.4 & $28.3-34.4$ & 38.0 & $34.3-41.6$ \\
\hline 25-OH-D, nmol/L & 45.7 & $41.2-50.3$ & 92.5 & 83.4-101.5 & 61.3 & $58.6-63.9$ & 28.8 & $26.0-31.6$ \\
\hline
\end{tabular}

Table 3

Frequency of Vitamin D deficiency and insufficiency by season.

\begin{tabular}{|c|c|c|c|c|c|c|}
\hline & & Winter & Spring & Summer & Autumn & Total \\
\hline \multirow{2}{*}{$\begin{array}{l}\text { Vitamin D deficient } \\
(25-\mathrm{OH}-\mathrm{D}>75 \mathrm{nmol} / \mathrm{L})\end{array}$} & $\mathrm{N}(\%)$ & $37(84)$ & $16(80)$ & $7(21)$ & $18(58)$ & $78(61)$ \\
\hline & adjusted residual & 3.9 & 1.9 & -5.5 & -0.3 & \\
\hline \multirow{2}{*}{$\begin{array}{l}\text { Vitamin D insufficient } \\
(25-\mathrm{OH}-\mathrm{D} 50-75 \mathrm{nmol} / \mathrm{L})\end{array}$} & $\mathrm{N}(\%)$ & $6(14)$ & $2(10)$ & $16(47)$ & $10(32)$ & $34(26)$ \\
\hline & adjusted residual & -2.4 & -1.8 & 3.2 & 0.9 & \\
\hline \multirow{2}{*}{$\begin{array}{l}\text { Vitamin D sufficient } \\
(25-\mathrm{OH}-\mathrm{D}<50 \mathrm{nmol} / \mathrm{L})\end{array}$} & $N(\%)$ & $1(2)$ & $2(10)$ & $11(32)$ & $3(10)$ & $17(13)$ \\
\hline & adjusted residual & -2.6 & -0.5 & 3.9 & -0.7 & \\
\hline
\end{tabular}


2008 (data of the ongoing incidence study in Switzerland, personal communication: Prof. Eugen J. Schoenle, Zürich) we estimated a total of about 280 children between the ages of $0-16$ years with T1D living in the Canton of Bern. We could therefore conclude that approximately $50 \%$ of the children with T1D living in the Canton of Bern participated in this study.

A most important finding is that the prevalence of vitamin D deficiency was higher in our cohort $(60.5 \%)$ than in previous studies analysing subjects with T1D (15-43\%) using the same cut-off values to define serum vitamin D status. The prevalence of vitamin D deficiency was $43 \%$ in an Australian study [19], about 25\% in an Italian study [21] and $15 \%$ in a recent study in US East Coast youth [20]. However, when focusing on the prevalence of vitamin D sufficiency, the data were similar: Bern: 13\%; Australia: $19 \%$; US East coast: $25 \%$. Thus the main difference is in the range of insufficiency (26-36\%) [19-21]. These overall differences might be explained by the variability of geographical environment, the age of the subjects, duration of diabetes (diagnosis vs. follow-up), glycaemic control etc. as recently suggested [20]. In contrast, 25D levels were usually above $50 \mathrm{nmol} / \mathrm{L}$ in young adults at diagnosis of T1D in Sweden [35].

It is not surprising to find a marked seasonal variability of 25D levels since UV light exposure is essential for vitamin D biosynthesis in the skin [36]. Only during the months of July, August and September were 25D levels sufficient for most patients. This is in line with the Swedish study showing similar month-to-month fluctuations of the 25D levels although at a higher concentration [35]. In T1D children of the US East Coast vitamin D deficiency was found in $47 \%$ during winter and in only $5 \%$ during summer [20]. One might argue that the much higher prevalence of vitamin D deficiency found even during the summer in our study is due to absence of vitamin D supplementation in

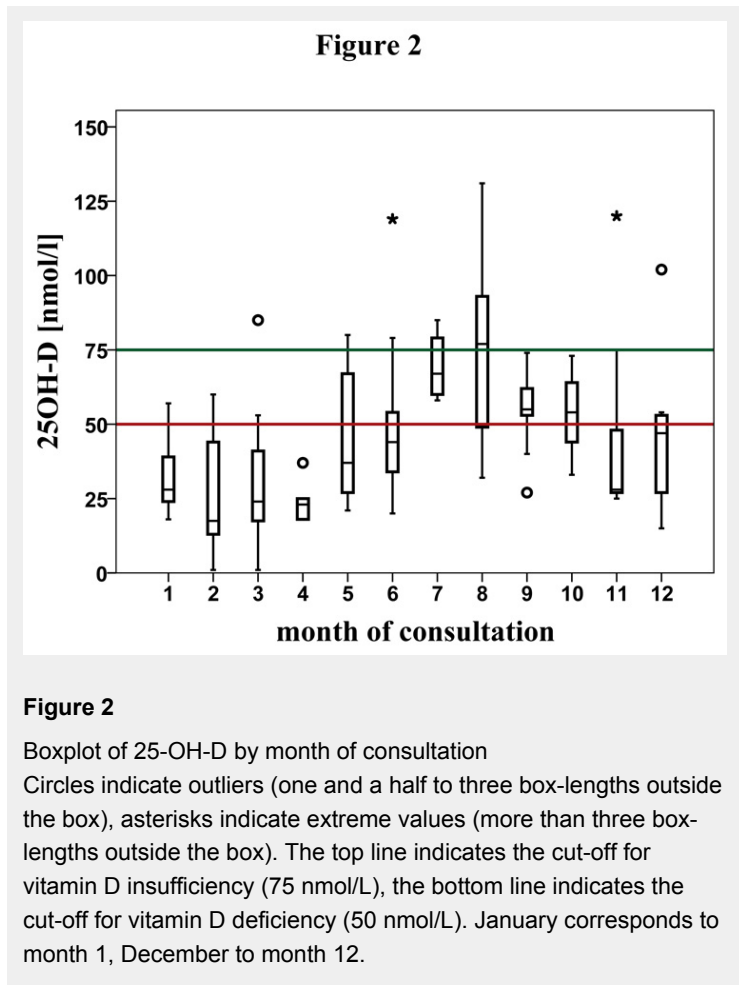

many Swiss foods compared to other countries such as the US. Also, outdoor activities may play a key role when comparing other studies with Swiss data.

An additional finding was that the prevalence of secondary hyperparathyroidism was very low in vitamin D deficient patients. In contrast, PTH levels never fell below 20 $\mathrm{pg} / \mathrm{ml}$ in our patients, which is clearly above the level of 10 $\mathrm{pg} / \mathrm{ml}$ expected for the continuous tonic secretion of PTH $[12,37]$, which suggests that the continuous tonic PTH secretion might be elevated in diabetic subjects. In adults, PTH levels are expected to rise steeply above $40 \mathrm{pg} / \mathrm{ml}$ at 25D levels below $50 \mathrm{nmol} / \mathrm{L}$ and above $50 \mathrm{pg} / \mathrm{ml}$ at $25 \mathrm{D}$ levels below $25 \mathrm{nmol} / \mathrm{L}$ [27]. This relationship seems to be less pronounced in healthy adolescents [12]. We have two possible explanations why PTH levels did not show the expected rise in diabetic children and adolescents. First, the PTH-vitamin D axis has a blunted response in diabetic patients, a finding supported by several studies [29, 31]. In one study a blunted response of PTH was associated with low magnesium levels and corrected after magnesium repletion [30]. Our patients, however, did not show any magnesium depletion. A blunted response of PTH would result in inadequately normal PTH levels with low ionised calcium. However, we did not find differences in ionised calcium levels between vitamin D deficient and vitamin D sufficient patients. Furthermore, the participants in our study had a mean calcium intake of $845 \mathrm{mg} / \mathrm{day}$, close to the recommended daily intake for age of $1200 \mathrm{mg}$ /day [38]. Since it is known that the clinical signs of vitamin D deficiency (rickets, hyperparathyroidism) are highly dependent on calcium intake [39], one can speculate that in our patients lacking PTH rise even in severely vitamin D insufficient individuals was due to near optimal oral calcium intake. However, no calcium balance studies were performed to investigate this hypothesis any further. In addition, increased tonic PTH secretion could have a protective effect on serum calcium concentrations. Second, hypocalcaemia was too mild to induce a rise in PTH in our patients. Physiologically the set-point in the inverse sigmoidal relationship between ionised calcium and PTH is around 1.22 $\mathrm{mmol} / \mathrm{L}$ and PTH secretion reaches a plateau at ionised calcium concentrations below $1.15 \mathrm{mmol} / \mathrm{L}$ [37]. The concentration of ionised calcium in our patients, however, was mostly above $1.2 \mathrm{mmol} / \mathrm{L}$ and only three patients had values below $1.15 \mathrm{mmol} / \mathrm{L}$. Hence, in our cohort we have not enough data to define both a top and bottom plateau of the sigmoidal relationship between iPTH and ionised calcium for a detailed description in comparison to a normal curve.

A clear limitation of our study is that no control group of non-diabetic children was included. However, similar studies in healthy children showed a prevalence of vitamin $\mathrm{D}$ deficiency in the same range (4-7, 10-12, 15-17, 40, 41). In the only existing Swiss study $15 \%$ of the participants aged between $11-16$ years (29\% if only adolescents of Tanner stage 4 and 5 were considered) had 25-OH levels below $30 \mathrm{nmol} / \mathrm{L}$ compared to $36 \%$ in our study [42]. Furthermore, a recent study in healthy German children and adolescents (who are in terms of customs and genetic background the closest to our study population) showed similar results, with $63 \%$ of the participants having $25-\mathrm{OH}-$ $\mathrm{D}$ levels below $50 \mathrm{nmol} / \mathrm{L}$ [41]. Another limitation of our 
study is that the effective time of sunshine exposure was not assessed for the individual patient.

In summary, we show that vitamin D deficiency is highly prevalent in young people with T1D attending our outpatient clinic, and that there is a marked seasonal fluctuation of serum 25D levels. Additionally, we found a low prevalence of secondary hyperparathyroidism in vitamin D deficient subjects. Knowing that vitamin D deficiency affects bone health, these findings raise the question whether vitamin D deficiency should be screened for and supplementation recommended in children with low levels. Since $25-\mathrm{OH}-\mathrm{D}$ levels above $37.5 \mathrm{nmol} / \mathrm{L}$ are necessary to prevent nutritional rickets, we suggest those children be treated according to AAP recommendations regardless of presence or absence of clinical symptoms and signs [43]. To prevent bone disease in adulthood, vitamin D supplementation may be considered even for children and adolescents with 25-OH-D levels between $37.5-75 \mathrm{nmol} / \mathrm{L}$. Further studies are needed to solve these questions and to identify mechanisms responsible for the low prevalence of secondary hyperparathyroidism in T1D subjects with low vitamin D levels.

We thank Dr. Chantal Cripe Mamie for proofreading our manuscript.

\section{Funding / potential competing interests}

No funding; no competing interests.

\section{References}

1 Holick MF. Vitamin D deficiency. N Engl J Med. 2007;357:266-81.

2 Malabanan A, Veronikis IE, Holick MF. Redefining vitamin D insufficiency. Lancet. 1998;351:805-6.

3 Baker MR, McDonnell H, Peacock M, Nordin BE. Plasma 25-hydroxy vitamin D concentrations in patients with fractures of the femoral neck. Br Med J. 1979;1:589.

4 Gordon CM, DePeter KC, Feldman HA, Grace E, Emans SJ. Prevalence of vitamin D deficiency among healthy adolescents. Arch Pediatr Adolesc Med. 2004;158:531-7.

5 El-Hajj Fuleihan G, Nabulsi M, Choucair M, Salamoun M, Hajj Shahine C, Kizirian A, et al. Hypovitaminosis D in healthy schoolchildren. Pediatrics. 2001;107:E53.

6 Tangpricha V, Pearce EN, Chen TC, Holick MF. Vitamin D insufficiency among free-living healthy young adults. Am J Med. 2002;112:659-62.

7 Weng FL, Shults J, Leonard MB, Stallings VA, Zemel BS. Risk factors for low serum 25-hydroxyvitamin D concentrations in otherwise healthy children and adolescents. Am J Clin Nutr. 2007; 86:150-8.

8 Specker BL, Ho ML, Oestreich A, Yin TA, Shui QM, Chen XC, et al. Prospective study of vitamin D supplementation and rickets in China. J Pediatr. 1992;120:733-9.

9 Gordon CM, Feldman HA, Sinclair L, Williams AL, Kleinman PK, Perez-Rossello J, et al. Prevalence of vitamin D deficiency among healthy infants and toddlers. Arch Pediatr Adolesc Med. 2008;162:505-12.

10 Looker AC, Dawson-Hughes B, Calvo MS, Gunter EW, Sahyoun NR. Serum 25-hydroxyvitamin D status of adolescents and adults in two seasonal subpopulations from NHANES III. Bone. 2002;30:771-7.

11 Lawson M, Thomas M. Vitamin D concentrations in Asian children aged 2 years living in England: population survey. BMJ. 1999;318:28.

12 Guillemant J, Le HT, Maria A, Allemandou A, Peres G, Guillemant S. Wintertime vitamin D deficiency in male adolescents: effect on para- thyroid function and response to vitamin D3 supplements. Osteoporos Int. 2001;12:875-9.

13 Nicolaidou P, Hatzistamatiou Z, Papadopoulou A, Kaleyias J, Floropoulou E, Lagona E, et al. Low vitamin D status in mother-newborn pairs in Greece. Calcif Tissue Int. 2006;78:337-42.

14 Pehlivan I, Hatun S, Aydogan M, Babaoglu K, Gokalp AS. Maternal vitamin $\mathrm{D}$ deficiency and vitamin $\mathrm{D}$ supplementation in healthy infants. Turk J Pediatr. 2003;45:315-20.

15 Du X, Greenfield H, Fraser DR, Ge K, Trube A, Wang Y. Vitamin D deficiency and associated factors in adolescent girls in Beijing. Am J Clin Nutr. 2001;74:494-500.

16 Lehtonen-Veromaa M, Mottonen T, Irjala K, Karkkainen M, LambergAllardt C, Hakola P, et al. Vitamin D intake is low and hypovitaminosis D common in healthy 9- to 15-year-old Finnish girls. Eur J Clin Nutr. 1999;53:746-51.

17 Outila TA, Karkkainen MU, Lamberg-Allardt CJ. Vitamin D status affects serum parathyroid hormone concentrations during winter in female adolescents: associations with forearm bone mineral density. Am J Clin Nutr. 2001;74:206-10.

18 Ward LM, Gaboury I, Ladhani M, Zlotkin S. Vitamin D-deficiency rickets among children in Canada. CMAJ. 2007;177:161-6.

19 Greer RM, Rogers MA, Bowling FG, Buntain HM, Harris M, Leong GM, et al. Australian children and adolescents with type 1 diabetes have low vitamin D levels. Med J Aust. 2007;187:59-60.

20 Svoren BM, Volkening LK, Wood JR, Laffel LM. Significant vitamin $\mathrm{D}$ deficiency in youth with type 1 diabetes mellitus. J Pediatr. 2009;154:132-4.

21 Pozzilli P, Manfrini S, Crino A, Picardi A, Leomanni C, Cherubini V, et al. Low levels of 25-hydroxyvitamin D3 and 1,25-dihydroxyvitamin D3 in patients with newly diagnosed type 1 diabetes. Horm Metab Res. 2005;37:680-3.

22 Gartner LM, Greer FR. Prevention of rickets and vitamin D deficiency: new guidelines for vitamin D intake. Pediatrics. 2003;111:908-10.

23 Holick MF. Resurrection of vitamin D deficiency and rickets. J Clin Invest. 2006;116:2062-72.

24 Hollis BW. Circulating 25-hydroxyvitamin D levels indicative of vitamin D sufficiency: implications for establishing a new effective dietary intake recommendation for vitamin D. J Nutr. 2005;135:317-22.

25 Dawson-Hughes B, Heaney RP, Holick MF, Lips P, Meunier PJ, Vieth R. Estimates of optimal vitamin D status. Osteoporos Int 2005;16:713-6.

26 Holick MF. High prevalence of vitamin D inadequacy and implications for health. Mayo Clin Proc. 2006; 81:353-73.

27 Thomas MK, Lloyd-Jones DM, Thadhani RI, Shaw AC, Deraska DJ, Kitch BT, et al. Hypovitaminosis D in medical inpatients. N Engl J Med. 1998;338:777-83.

28 Hofbauer LC, Brueck CC, Singh SK, Dobnig H. Osteoporosis in patients with diabetes mellitus. J Bone Miner Res. 2007;22:1317-28.

29 Fogh-Andersen N, McNair P, Moller-Petersen J, Madsbad S. Lowered serum ionized calcium in insulin treated diabetic subjects. Scand J Clin Lab Invest Suppl. 1983;165:93-7.

30 Saggese G, Federico G, Bertelloni S, Baroncelli GI, Calisti L. Hypomagnesemia and the parathyroid hormone-vitamin $\mathrm{D}$ endocrine system in children with insulin-dependent diabetes mellitus: effects of magnesium administration. J Pediatr. 1991;118:220-5.

31 Schwarz P, Sorensen HA, Momsen G, Friis T, Transbol I, McNair P. Hypocalcemia and parathyroid hormone responsiveness in diabetes mellitus: a tri-sodium-citrate clamp study. Acta Endocrinol (Copenh). 1992;126:260-3.

32 Association AD. Diagnosis and classification of diabetes mellitus. Diabetes Care. 2004;27:S5-10.

33 Prader A, Largo RH, Molinari L, Issler C. Physical growth of Swiss children from birth to 20 years of age. Helvetica Paediatrica Acta. 1989;Suppl 52:1-125.

34 Kromeyer-Hauschild K, Wabitsch M, Kunze D. Perzentile für den Body-mass-Index für das Kindes- und Jugendalter unter Heranziehung verschiedener deutscher Stichproben. Monatsschrift für Kinderheilkunde. 2001;149:807-18. 
35 Littorin B, Blom P, Scholin A, Arnqvist HJ, Blohme G, Bolinder J, et al. Lower levels of plasma 25-hydroxyvitamin D among young adults at diagnosis of autoimmune type 1 diabetes compared with control subjects: results from the nationwide Diabetes Incidence Study in Sweden (DISS). Diabetologia. 2006;49:2847-52.

36 Ganong WF. Review of Medical Physiology. 20th Ed. Lange-McGraw Hill, New York, 2001.

37 Conlin PR, Fajtova VT, Mortensen RM, LeBoff MS, Brown EM. Hysteresis in the relationship between serum ionized calcium and intact parathyroid hormone during recovery from induced hyper- and hypocalcemia in normal humans. J Clin Endocrinol Metab. 1989;69:593-9.

38 NIH Consensus conference. Optimal calcium intake. NIH Consensus Development Panel on Optimal Calcium Intake. JAMA. 1994; 272:1942-8.

39 Allgrove J. Calcium and Bone Disorders in Children and Adolescents. Karger Publ., Basel, 2009.

40 Bischoff-Ferrari HA, Giovannucci E, Willett WC, Dietrich T, DawsonHughes B. Estimation of optimal serum concentrations of 25-hydroxyvitamin D for multiple health outcomes. Am J Clin Nutr. 2006;84:18-28.

41 Hintzpeter Birte CS-N, Manfred J. Müller, Liane Schenk and Gert B. M. Mensink. Higher Prevalence of Vitamin D Deficiency Is Associated with Immigrant Background among Children and Adolescents in Germany. J Nutr. 2008;138:1482-90.
42 Ginty F CC, Michaud P-A, et al. Effects of usual nutrient intake and vitamin D status on markers of bone turnover in Swiss adolescents. Eur J Clinical Nutri. 2004;58:1257-65.

43 Misra M PD, Petryk A, Ferrez Collett-Solberg P, Kappy M. Vitamin D Deficiency in Children and its Management: Review of Current Knowledge and Recommendations. Pediatrics. 2008;122:398-417.

\section{Appendix}

Calcium intake was assessed by asking the participants how many units of various dairy products they usually took during a week and by calculating the corresponding calcium intake by day. The sample units of dairy products were shown to the participants on a visual scale. Calcium intake through mineral water or calcium supplements was calculated separately and the result added to the intake resulting from dairy products. We based our calculations of calcium content of dairy products and mineral water on the following assumptions:

\begin{tabular}{|l|l|l|}
\hline Product & Unit & Calcium content \\
\hline Milk & $1 \mathrm{dl}$ & $120 \mathrm{mg}$ \\
\hline Joghurt & $150 \mathrm{~g}$ & $215 \mathrm{mg}$ \\
\hline Cottage cheese & $200 \mathrm{~g}$ & $180 \mathrm{mg}$ \\
\hline Soft cheese & $40 \mathrm{~g}$ & $20 \mathrm{mg}$ \\
\hline Medium-hard cheese & $40 \mathrm{~g}$ & $28 \mathrm{mg}$ \\
\hline Hard cheese & $40 \mathrm{~g}$ & $48 \mathrm{mg}$ \\
\hline High Ca mineral water (i.e.Valser) & $1 \mathrm{dl}$ & $55 \mathrm{mg}$ \\
\hline Medium Ca mineral water (i.e. Aproz) & $1 \mathrm{dl}$ & $30 \mathrm{mg}$ \\
\hline Low Ca mineral water (i.e. Evian) & $1 \mathrm{dl}$ & $10 \mathrm{mg}$ \\
\hline
\end{tabular}

